\title{
Alireza Khosrowzadeh, Aliashgar Norouzi, Rika Gyselen, Hossein Habibi. "Administrative bullae from tappe Bardakoon, a newly found Late Sasanian administreative centre"
}

\section{Rémy Boucharlat}

\section{(2) OpenEdition}

\section{Journals}

Édition électronique

URL : https://journals.openedition.org/abstractairanica/53367

DOI : 10.4000/abstractairanica.53367

ISSN : 1961-960X

Éditeur :

CNRS (UMR 7528 Mondes iraniens et indiens), Éditions de l'IFRI

Référence électronique

Rémy Boucharlat, « Alireza Khosrowzadeh, Aliashgar Norouzi, Rika Gyselen, Hossein Habibi.

"Administrative bullae from tappe Bardakoon, a newly found Late Sasanian administreative centre" », Abstracta Iranica [En ligne], Volume 42-43 | 2021, document 64, mis en ligne le 30 décembre 2021, consulté le 12 décembre 2022. URL : http://journals.openedition.org/abstractairanica/53367 ; DOI : https://doi.org/10.4000/abstractairanica.53367

Ce document a été généré automatiquement le 12 décembre 2022.

Tous droits réservés 


\title{
Alireza Khosrowzadeh, Aliashgar Norouzi, Rika Gyselen, Hossein Habibi. "Administrative bullae from tappe Bardakoon, a newly found Late Sasanian administreative centre"
}

\author{
Rémy Boucharlat
}

\section{RÉFÉRENCE}

Alireza Khosrowzadeh, Aliashgar Norouzi, Rika Gyselen, Hossein Habibi.

"Administrative bullae from tappe Bardakoon, a newly found Late Sasanian administreative centre”, Iranica Antiqua LV, 2020, p. 165-220.

1 Situé dans une région peu explorée dans la province Chahār Mahāl va Bakhtiyāri, à l'ouest d'Isfahan, département de Farsan à une altitude moyenne de $2000 \mathrm{~m}$ environ, Tepe Bardakoon est un tappeh de $15 \mathrm{~m}$ de diamètre sur une colline naturelle, qui domine la plaine de 30m environ. La céramique de surface rend compte d'une occupation depuis l'époque élamite jusqu'à fin sassanide (drachme de Xusro II).

2 Largement pillé, le site a été l'objet de fouilles régulières dont cet article rend compte pour deux saisons 2017 et 2018. Deux sondages 10x10m ont révélé des éléments de murs épais de $2.50 \mathrm{~m}$, fait de briques crues de $40 \times 40 \times 10 \mathrm{~cm}$ and $37.5 \times 37.5 \times 7 \mathrm{~cm}$, des formats connus à l'époque sassanide (mais aussi dès l'époque parthe). La céramique est constituée de récipients utilitaires et de grands bols à décor incisé, de types connus à l'époque sassanide. 
3 Mais la trouvaille de première importance est celle d'un large corpus of 559 bulles et empreintes de sceaux (figs. 8-12) concentrées dans une pièce. La plupart montre le trou dans lequel passait la corde qui permettait d'attacher ces bulles à une jarre. Quelques exemplaires sans trou portent au revers des traces imprimées de textiles et de sac.

4 Parmi ces empreintes, on relève 22 impressions de sceaux administratifs dont est donné le catalogue précis dans lequel on reconnaît la science immense de Rika Gyselen qui s'efforce de former des élèves. Voir son apport dans l'article dans Res Orientales XXVIII, publié la même année (cf. le compte rendu dans ce même numéro d'Abstracta Iranica).

\section{AUTEURS}

RÉMY BOUCHARLAT

UMR 5133 CNRS-Université de Lyon 